\title{
ANÁLISE DO DESEMPENHO TÉRMICO DE UM SISTEMA DE AQUECEDOR SOLAR CONVENCIONAL NA CIDADE DE VITÓRIA DA CONQUISTA
}

\author{
Jamille Teixeira Rocha - jamilleteixeira.rocha@gmail.com \\ Instituto Federal da Bahia \\ Auerê Vasconcelos Veras - veras@auere.com.br \\ Instituto Federal da Bahia
}

Caroline Matos Pinheiro - carolmatos_@hotmail.com

Instituto Federal da Bahia 

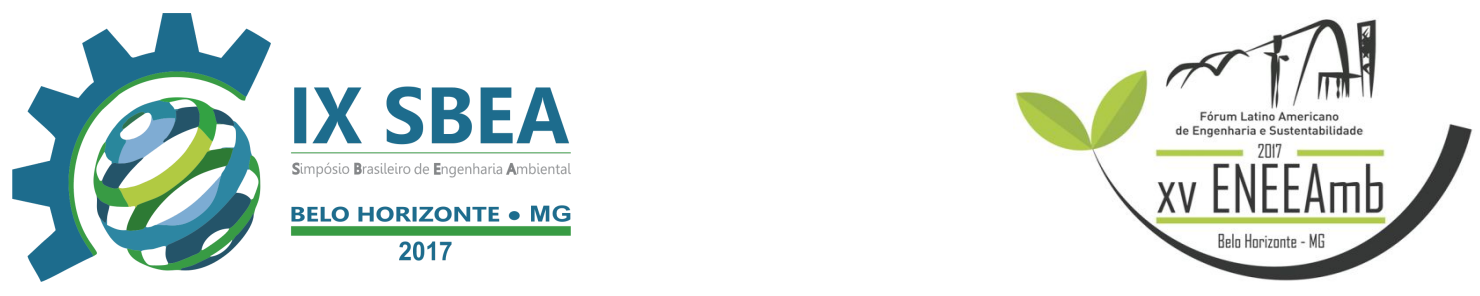

\section{RESUMO}

O presente trabalho possui como objetivo avaliar o desempenho de um Sistema de Aquecedor Solar (SAS) convencional para fins residenciais instalado no Instituto Federal da Bahia (IFBA), campus de Vitória da Conquista. A proposta da pesquisa em questão é calcular a energia coletada pelo coletor, a eficiência do coletor e as perdas do sistema, a partir de dados de temperatura da água que circula pelo SAS e dados de radiação solar extraídos da estação meteorológica instalada no Instituto. A avaliação foi feita com os registros da primeira semana de Fevereiro de 2016 e da segunda semana de Maio de 2016. O objetivo do estudo é comprovar o desempenho energético do sistema instalado, incentivando a prática renovável.

Palavras Chave: Eficiência energética. Energia Solar. Sistema de Aquecedor Solar.

\section{INTRODUÇÃO}

As usinas hidrelétricas correspondem a $75 \%$ da potência instalada no país e geraram, em 2005, 93\% da energia elétrica requerida no Sistema Interligado Nacional. De acordo o Centro de Referência para Energia Solar e Eólica, o Brasil possui média anual de energia incidente para geração de energia solar entre $4 \mathrm{kwh} / \mathrm{m}^{2}$.dia e $5 \mathrm{kwh} / \mathrm{m}^{2}$.dia (ATLAS, 2017b). Com a crise energética ocorrida no Brasil, foi de suma importância o investimento em outros tipos de energia com fontes renováveis, para compor o novo quadro da matriz energética do Brasil.

O Boletim Mensal de Monitoramento do Sistema Elétrico Brasileiro (2016) traz que, no mês de Janeiro de 2016, a capacidade instalada total de geração de energia elétrica do Brasil atingiu 141.684 MW, e desse total, 6MW foram provenientes de fonte solar.

Os sistemas termo-solares são capazes de suprir a eletricidade para o aquecimento de água, atuando como uma alternativa que causa menos danos ambientais e retorno financeiro, pela economia de energia elétrica. O Brasil tem uma ótima localização, entre a linha do Equador e o Trópico de Capricórnio, que recebe uma média 

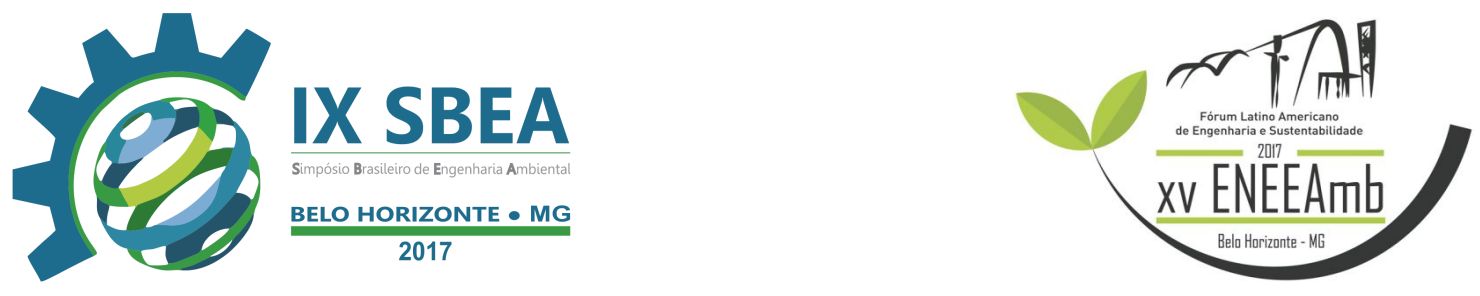

global de irradiação de 4200-6700 kWh/m² em seu território (ATLAS,2017a). Com isso, a energia solar para o aquecimento de água pode ser aproveitada de forma eficiente.

O chuveiro elétrico tem uma participação de $24 \%$ do consumo total de energia elétrica na classe residencial no Brasil e é considerado o equipamento que contribui, de forma acentuada, para o aumento da demanda de potência ao sistema elétrico no horário de ponta (ELETROBRÁS PROCEL, 2012). Nesse contexto, o correto aproveitamento dos recursos naturais, principalmente água e energia, se institui como uma ação fundamental para o desenvolvimento sustentável da sociedade.

O aquecimento gerado pelo Sistema de Aquecedor Solar (SAS) provoca o movimento convectivo natural, que consiste na transferência da água de um local para outro devido à diferença de densidades entre a água quente (mais leve) e água fria (mais pesada). Esse movimento ocorre até que a água existente no SAS, composto por boiler e coletor, atinja o equilíbrio térmico.

A proposta da pesquisa em questão é constatar a eficiência de um SAS convencional instalado na cidade de Vitória da Conquista/BA, cujo clima tropical é amenizado pela relativa altitude do lugar (cerca de $1000 \mathrm{~m}$ acima do nível do mar). A cidade registra as temperaturas mais frias da Bahia, chegando a marcar $6,2^{\circ} \mathrm{C}$ em 2006 (VITÓRIA DA CONQUISTA, 2017). A análise foi feita levando em conta os dados de uma semana de um mês considerado quente e os dados de uma semana de um mês considerado frio, no ano de 2016, e através desse resultado, incentivar a prática do uso de energias renováveis na cidade.

\section{METODOLOGIA}

O presente trabalho irá averiguar o desempenho térmico de um SAS convencional instalado no Instituto Federal da Bahia (IFBA), campus de Vitória da Conquista. A primeira etapa do estudo constituiu de um levantamento de dados obtidos a partir do SAS, da marca Soletrol, e da estação meteorológica, da marca Davis Vantage 

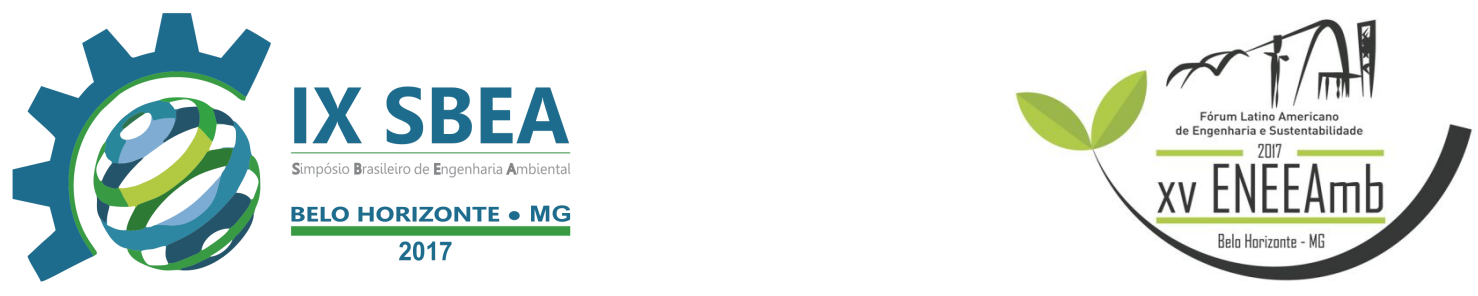

Pro2a, acomodada próximo ao sistema de aquecimento. Os dados colhidos foram armazenados em um Sistema de Aquisição de Dados (DAQ).

O DAQ registrava diariamente, de 10 em 10 minutos, informações como temperatura do ar e radiação solar, provenientes da estação meteorológica; e de 5 em 5 minutos temperaturas da água na entrada e saída do boiler e do coletor solar, provenientes de sensores de temperatura, do tipo DS18B20, instalados no SAS.

De posse dos dados efetivamente captados com o DAQ, foi delimitado um intervalo de tempo entre os meses de Fevereiro e Maio de 2016 para o estudo. A escolha desse intervalo deu-se pela posse mais completa de registros armazenados. Com essa base de dados de 4 meses, foi feito uma média aritmética mensal das temperaturas do ar registradas, objetivando determinar o mês de maior e menor temperatura dentro desse intervalo. O mês de Fevereiro foi o mais quente e Maio o mês mais frio.

A partir daí, escolheu-se os dados supracitados da semana do dia 02/02/16 até 08/02/16 e, da semana do dia 10/05/16 até 16/05/16, para a análise. Como os dados eram registrados com uma variação de 10 e 5 minutos, foi feito uma média aritmética para a determinação de um valor médio para as temperaturas da água na entrada e saída do boiler e do coletor, assim como para a determinação de um valor médio para a radiação solar, num intervalo de 1 hora. $\mathrm{O}$ período de tempo considerado para essa análise foi entre 7:30 hs e 15:30 hs. Por fim, foram calculados a energia coletada pelo coletor, a eficiência do coletor solar e o coeficiente global de perdas.

\section{RESULTADOS E DISCUSSÃO}

A área da placa solar utilizada é de $1,03 \mathrm{~m}^{2}$, e como o sistema é composto de duas placas, a área total resultou em 2,06 $\mathrm{m}^{2}$. A capacidade do boiler é de 200 litros. Nos cálculos, foram também utilizados dados coletados pela estação meteorológica e pelos sensores instalados no SAS. Os resultados apresentados foram obtidos através da análise do período de uma semana para os meses de Fevereiro e Maio do ano de 2016. 

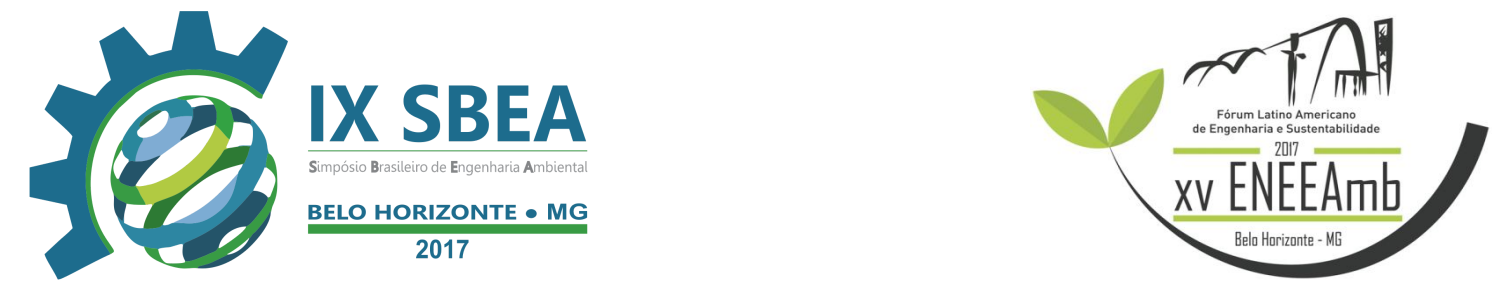

\subsection{ENERGIA ÚTIL RECOLHIDA PELO COLETOR}

No SAS de água, a conversão da radiação solar em calor é feita por meio de coletores solares no qual, a água tem sua energia interna aumentada, refletindo no incremento da temperatura do fluido. Segundo Georgi (2015), o cálculo da energia coletada pelo coletor é dado de acordo a Equação (1), em que $Q_{c}$ é o calor útil recolhido, $m$ a massa do fluido, $C_{p}$ o calor específico do fluido, $T_{c o}$ temperatura do coletor externa, $T_{c i}$ a temperatura do coletor interna.

$$
Q_{c}=m \cdot C_{p} \cdot T_{c o}-T_{c i}
$$

As figuras 1 e 2 mostram a energia útil recolhida pelo coletor diariamente nos meses de Fevereiro e Maio, respectivamente.

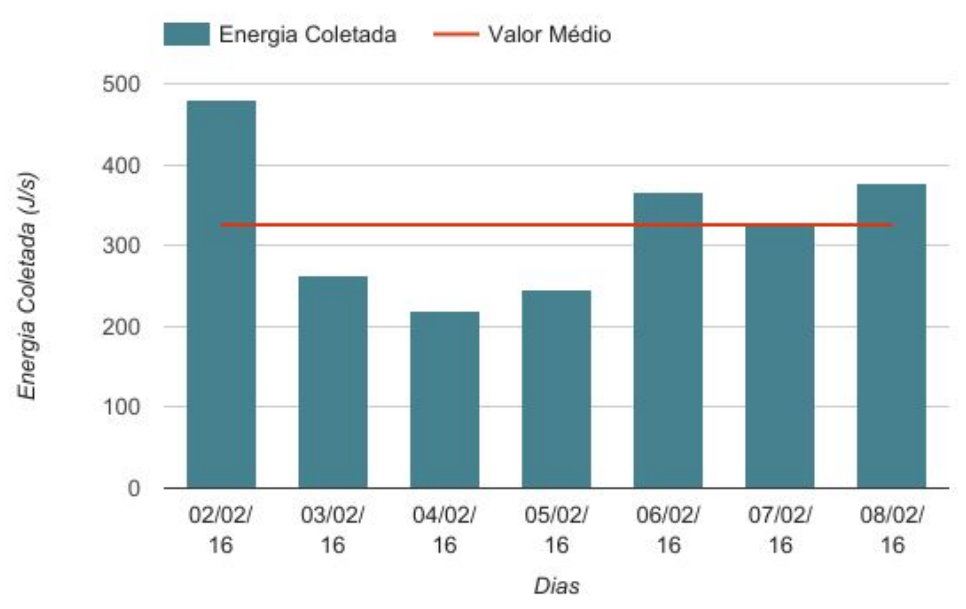

Figura 1 - Energia recolhida pelo coletor no mês de Fevereiro

O mês de Fevereiro, conforme Figura 1, por ser o mês com representatividade maior nas temperaturas, possibilitou uma quantidade significativa de energia coletada pelo coletor. Seu maior valor foi de $479,24 \mathrm{~J} / \mathrm{s}$ no $1^{\mathrm{o}}$ dia a ser realizado a coleta, isso se deve ao fato de que o dia 02 de Fevereiro teve a maior média de radiação solar da 

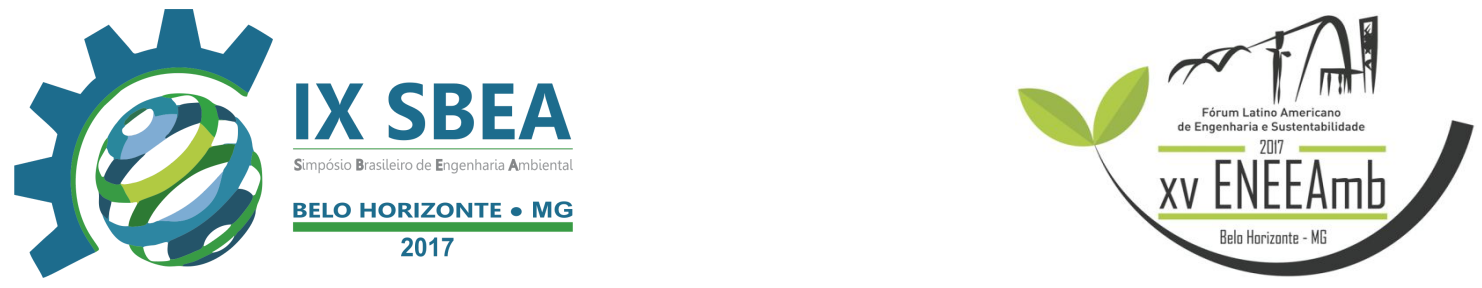

semana, com um valor de $833,40 \mathrm{~W} / \mathrm{m}^{2}$. A média semanal da energia coletada ficou em $345,45 \mathrm{~J} / \mathrm{s}$.

A Figura 2 mostra a energia coletada calculada no mês de Maio. Este mês possuía as temperaturas mais amenas dentro dos dados disponíveis. Verifica-se uma queda na energia coletada quando comparada ao mês de Fevereiro, devido à queda na temperatura e o menor índice de radiação solar ocorridos no mês de Maio.

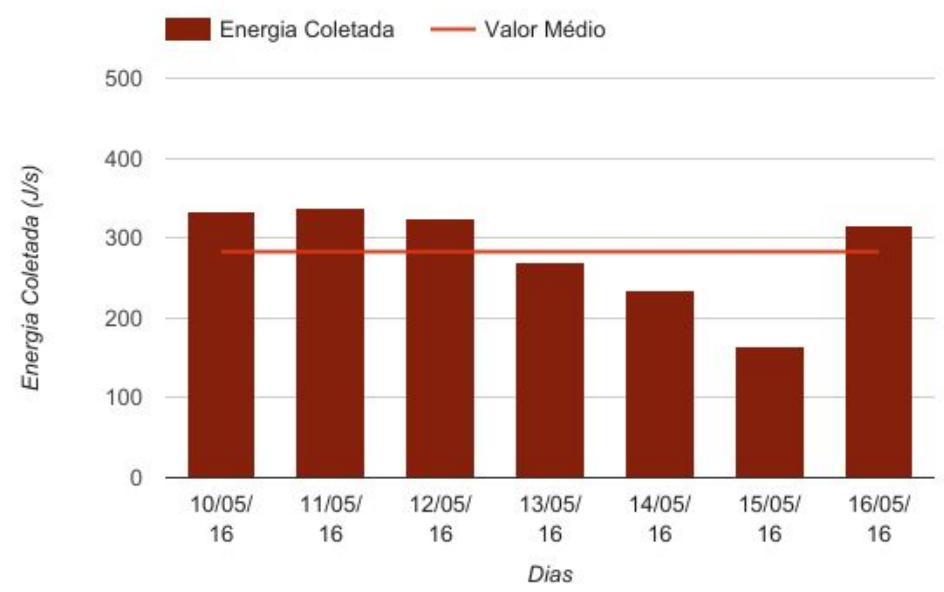

Figura 2 - Energia recolhida pelo coletor no mês de Maio

No mês de Maio, o maior valor de energia coletada foi de 338,21 J/s, correspondendo ao $2^{\circ}$ dia da análise, com uma média de radiação de $503,65 \mathrm{~W} / \mathrm{m}^{2}$. Já a média semanal deste mês ficou em torno de $282,84 \mathrm{~J} / \mathrm{s}$.

\subsection{EFICIÊNCIA DO COLETOR}

A eficiência permite determinar a quantidade de energia que o sistema consegue reter. A eficiência do coletor pode ser adquirida através da Equação (2). Nela, $\eta_{c}$ é eficiência do coletor solar, $m$ a massa do fluido, $C_{p}$ o calor específico do fluido, $T_{c o}$ temperatura do coletor externa, $T_{c i}$ a temperatura do coletor interna, $A_{c}$ a área do coletor e $G$ radiação solar. 

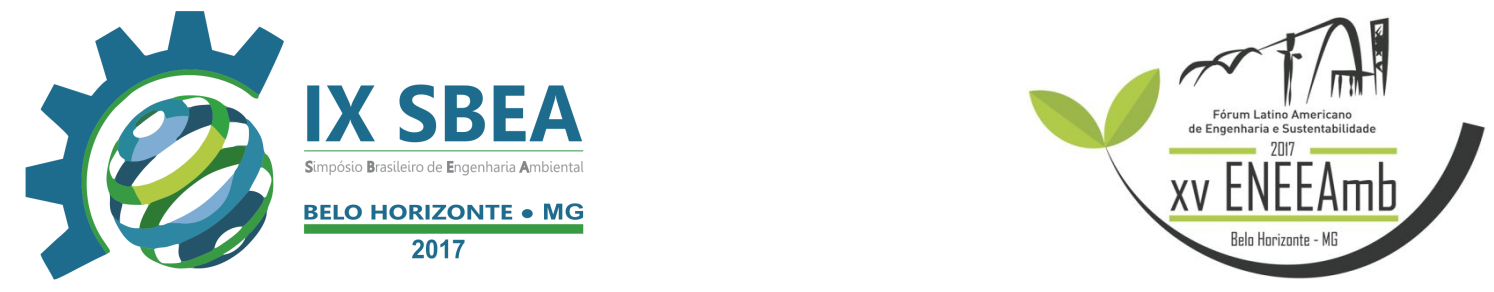

$$
\eta_{c}=\left[m \cdot C_{p} \cdot\left(T_{c o}-T_{c i}\right)\right] / A_{c} \cdot G
$$

Para o cálculo da eficiência do coletor utilizou-se a metodologia de Georgi (2015). Como o sistema possui dois coletores em série, a eficiência do coletor e sistema está proporcional ao número de coletores.

Na Figura 3, verifica-se que o dia 02 obteve a maior eficiência do coletor no mês de Fevereiro, com um valor de 30,66\%. A água no interior do coletor sofreu a maior variação média de temperatura e uma alta incidência de radiação solar, em torno de $833,40 \mathrm{~W} / \mathrm{m}^{2}$. A média semanal deste mês foi de 25,32\%. O menor valor de eficiência foi de $22,63 \%$, obtido no dia 04 , que pode ser justificado devido a uma baixa variação de temperatura média da água em conjunto com uma baixa incidência de radiação solar, cerca de $475,17 \mathrm{~W} / \mathrm{m}^{2}$.

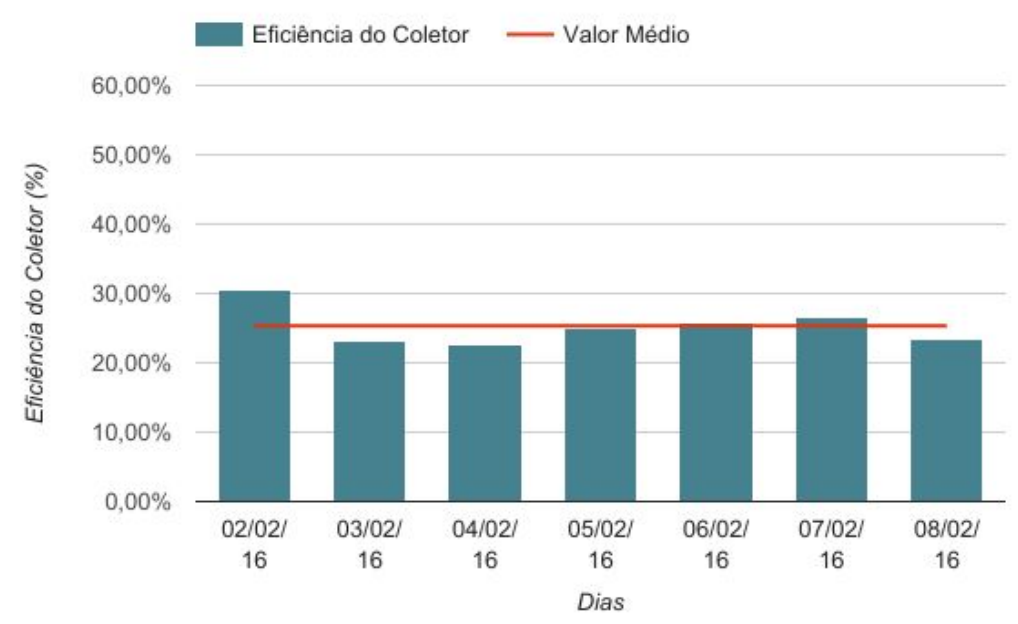

Figura 3 - Eficiência do coletor no mês de Fevereiro

$\mathrm{Na}$ Figura 4, tem-se a eficiência do coletor no mês de Maio. O maior valor de eficiência foi 55,74\%, no dia 12 . A média semanal foi de $43,09 \%$ e, o menor valor de eficiência foi 27,82\%, no dia 15. Na segunda semana de Maio, os dias 10, 11 e 12 tiveram a maior incidência de radiação, ocasionando uma maior variação de temperatura 

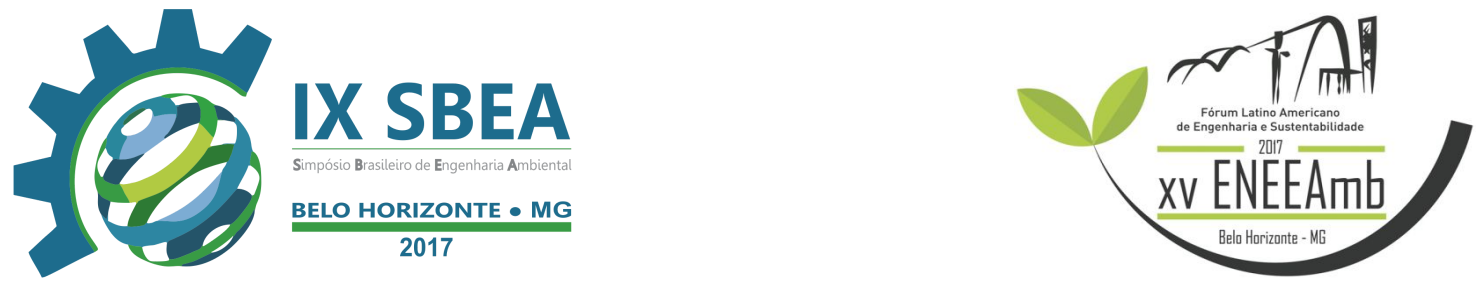

média da água e consequentemente, elevação da eficiência do coletor nesses dias.

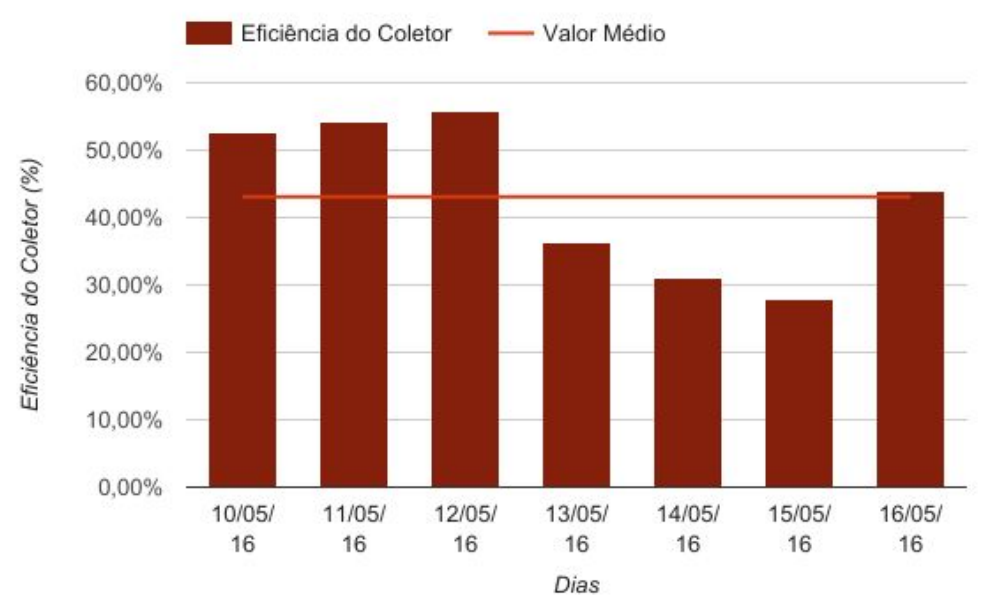

Figura 4 - Eficiência do coletor no mês de Maio

Apesar das temperaturas mais amenas terem acontecidos no mês de Maio, é aceitável essa variação na eficiência, pois houve a escolha de apenas uma semana dentro do mês, e nesta semana, houveram 3 dias com temperaturas distintas dos demais dias.

\subsection{COEFICIENTE GLOBAL DE PERDAS}

O coletor solar sofre com a perdas técnicas, em que parte da energia captada pelo coletor é transferida para a atmosfera por meio da radiação, condução e convecção, devido à diferença de temperatura entre os meios. Lopo (2010 apud Guerra e Varella, 2014), afirma que o coeficiente global de perdas é o parâmetro capaz de relacionar todas as perdas de um sistema. De acordo a Equação (3), $U_{p}$ corresponde ao coeficiente global de perdas, $P_{p}$ a potência perdida pelo coletor, $A_{c}$ é a área do coletor, $T_{p}$ é a temperatura média da placa e $T_{A}$ a temperatura ambiente.

$$
U_{p}=\frac{P_{p}}{A_{c} \cdot\left(T_{p}-T_{A}\right)}
$$

A Figura 5 traz a média do coeficiente global de perdas do coletor em 

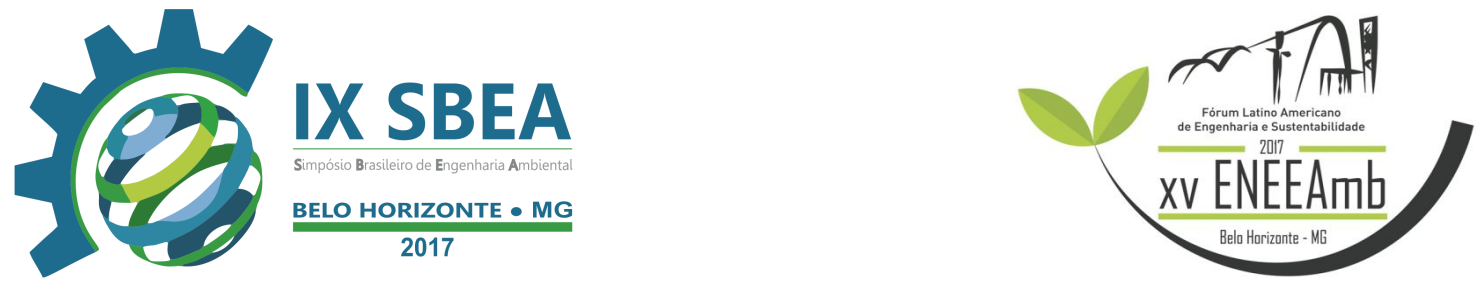

fevereiro. O maior valor para o coeficiente de perdas foi cerca de $38,23 \mathrm{~W} / \mathrm{m}^{2}{ }^{\circ} \mathrm{C}$, no dia 02. Já o menor valor foi de $15,33 \mathrm{~W} / \mathrm{m}^{2}{ }^{\circ} \mathrm{C}$, no dia 04 . A média semanal foi de 20,60 $\mathrm{W} / \mathrm{m}^{2}{ }^{\circ} \mathrm{C}$.

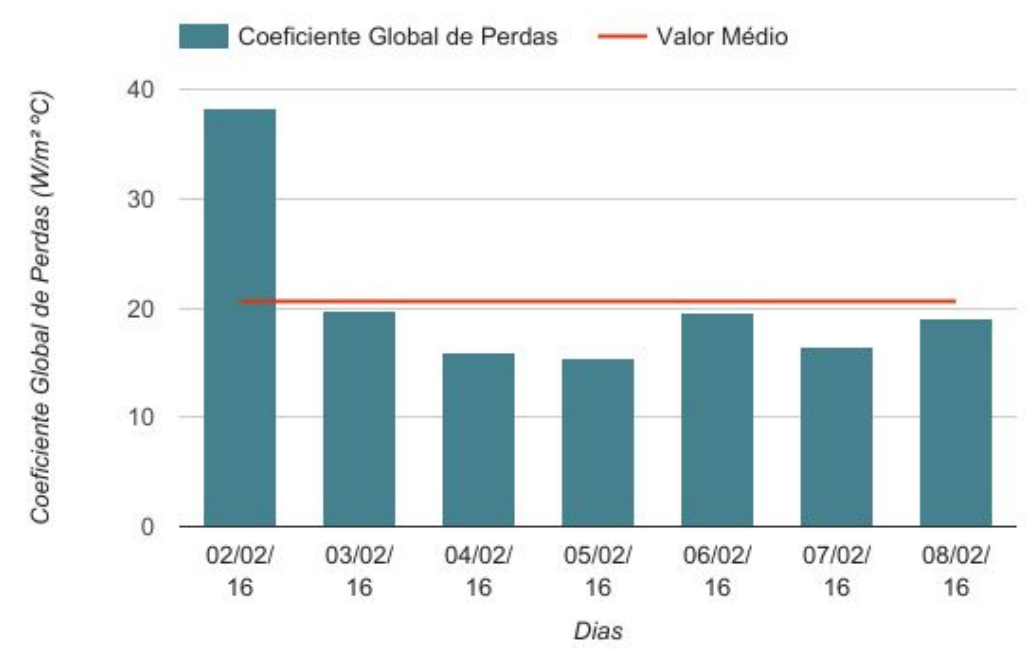

Figura 5 - Coeficiente global de perdas do mês de Fevereiro

O elevado valor do coeficiente global de perdas no $1^{\circ}$ dia do experimento deve-se ao alto índice de radiação nesse dia, com cerca de $833,40 \mathrm{~W} / \mathrm{m}^{2}$. Como a potência absorvida pela placa é diretamente proporcional à radiação, houve uma elevada absorção de energia, como pode ser visualizada na Figura 1, porém o sistema não se mostrou eficiente em retê-la.

O coeficiente global de perdas do mês de Maio é representado na Figura 6. O valor mais elevado de perdas foi no dia $16 \mathrm{com} 13,27 \mathrm{~W} / \mathrm{m}^{2}{ }^{\circ} \mathrm{C}$. O menor valor de perdas, - 0,93 W/m ${ }^{2}{ }^{\circ} \mathrm{C}$, ocorreu no dia 15. De acordo a Figura 2, o dia 15 foi o que apresentou menor valor de energia coletada, além disso teve o índice mais baixo de radiação solar dessa semana, 227,23 W/m². Com a baixa absorção de energia pela placa e incidência de radiação no dia, o coeficiente de perdas foi mínimo, representado pelo valor negativo. A média semanal foi de $9,54 \mathrm{~W} / \mathrm{m}^{2}{ }^{\circ} \mathrm{C}$. 

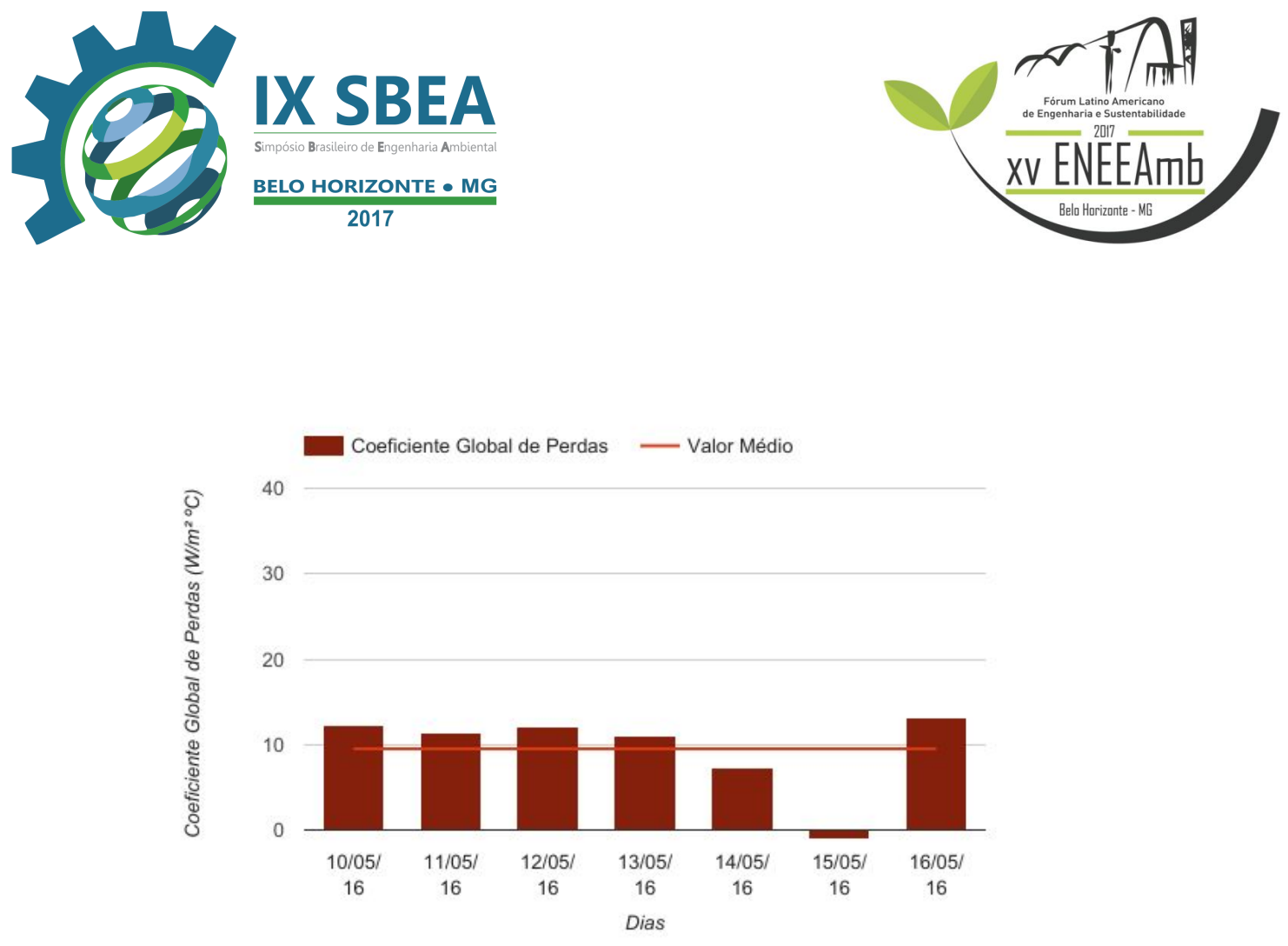

Figura 6 - Coeficiente global de perdas do mês de Maio

Com a análise dos resultados, percebeu-se que o mês de Fevereiro possuía elevado valor de coeficiente global de perdas. Isso resultou diretamente na eficiência do coletor, pois esta depende da energia útil recolhida pelo coletor e da incidência de radiação. O mês de Maio obteve menor energia útil recolhida, menor índice de radiação, menor coeficiente global de perdas e maior eficiência do coletor.

\section{CONCLUSÕES}

Devido a análise ter sido realizada em apenas uma semana dos meses de fevereiro e março, dentro de um intervalo de tempo e submetida a variações climáticas que não são controladas, pode-se considerar que os resultados estão dentro do esperado.

A partir dos resultados encontrados ficou notório que a eficiência do coletor depende diretamente da incidência de radiação solar, da energia útil absorvida, da variação da temperatura da água e do coeficiente global de perdas. O mês de Fevereiro foi o de maior absorção de energia, porém o que possui maior perda, influenciando na eficiência do coletor nesse determinado mês. Já Maio foi o mês de menor coeficiente global de perdas, isso mostra que o sistema conseguiu reter mais energia, influenciando na eficiência do coletor neste mês. 

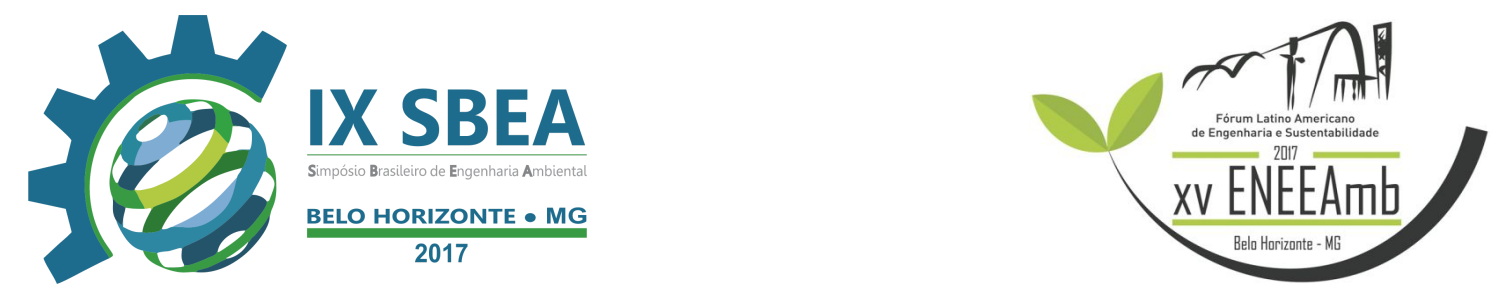

\section{REFERÊNCIAS BIBLIOGRÁFICAS}

ATLAS brasileiro de energia solar. Disponível em: http://ftp.cptec.inpe.br/labren/publ/livros/brazil_solar_atlas_R1.pdf Acesso em: 10 maio. 2017a.

ATLAS do potencial eólico brasileiro. Disponível em: http://www.cresesb.cepel.br/publicacoes/download/atlas_eolico/Atlas Acesso em: 10 maio. $2017 b$.

MINISTÉRIO de minas e energia. Boletim Mensal de Monitoramento do Sistema Elétrico $\quad$ Brasileiro. $2016 . \quad$ Disponível em: http://www.mme.gov.br/documents/10584/3308684/Boletim+de+Monitoramento+do+S istema+El\%C3\%A9trico+-+Janeiro-2016.pdf Acesso em: 15 maio. 2017.

ELETROBRAS PROCEL. Energia Solar para aquecimento de água no Brasil. Rio de Janeiro: Eletrobras, 2012. 240 p.

GUERRA, M, I, S. e VARELlA, F, K, O, M. Análise Do Desempenho Térmico De Um Sistema De Aquecimento Solar De Baixo Custo Na Cidade De Mossoró (RN). HOLOS, Ano 30, Vol. 4, 2014.

GEORGI, A, L, V. Aquecimento solar de água - Desempenho e racionalização de materiais e energia alternativa fundamental para o desenvolvimento sustentável. Curitiba, 118 p., 2015. Tese (Doutorado em Engenharia e Ciência dos Materias) Universidade Federal do Paraná.

LOPO, A, B. Análise do desempenho térmico de um sistema de aquecimento solar de baixo custo. Natal, 82 p., 2010. Dissertação (Mestrado em Engenharia Mecânica) Universidade Federal do Rio Grande do Norte.

VITÓRIA da conquista. Prefeitura Municipal de Vitória da Conquista. Disponível em: http://www.pmvc.ba.gov.br/geografia Acesso: 12 maio. 2017. 